\title{
BIRDS AND KHOESĀN: LINKING SPIRITS AND HEALING WITH DAY-TO-DAY LIFE
}

\author{
Chris Low
}

Reminiscent of other recent ethno-ornithologies, the following account considers bird naming, birds in folklore and birds as portentous messengers (Tidemann and Gosler 2010; Le Roux and Sellato 2006). Less typically, however, I locate these themes within a more fundamental interest in how bird encounter moves into meaning and use. The movement begins with KhoeSān recognizing certain powerful characteristics or associations in particular birds. These powerful characteristics are then worked into everyday contexts of KhoeSān life, ranging from village gossip to hunting plans to the use of potent bird parts in healing. My focus is on how living in particular ways in particular environments lends itself to certain forms of knowledge and praxis. I reflect on ways of being in 'nature' and understanding the nature of potency in KhoeSān life.

Potency is a phenomenon frequently written about in contexts of Bushman spirituality, shamanism, rock art and healing dances. ${ }^{1}$ It nevertheless remains poorly defined. Understanding potency is important not only in academic contexts but also because ideas of potency play a considerable role in KhoeSān understandings of illness and use of animal- and plant-based remedies. Although Khoe speakers use far more animals in their medicine than Ju/'hoansi, which may indicate the influence of African neighbours, animals are important to all, and the thinking behind animal use and around issues of potency reveals strong continuities across the KhoeSān. ${ }^{2}$

Scholars writing on Bushman spirit and potency frequently work across a range of sources including anthropology, rock art and the late nineteenth-century Bleek and Lloyd archive of /Xam Bushmen. To engage with this research and better understand potency, I similarly supplement my findings with this wider material. My analysis covers Khoekhoe herders and San (or Bushman) hunter-gatherers of Botswana, Namibia and South Africa, and stems from over two years of

Following academic training in archaeology and the history of medicine, in 1999 Chris Low undertook his interdisciplinary DPhil at Oxford, where currently he is based within the African Studies Centre as a post-doctoral researcher working on African medicine and KhoeSān environmental relationships, epistemology, ontology and (most recently) heritage. Email: chris. low@africa.ox.ac.uk

${ }^{1}$ Amongst the many scholars who write about potency, the prolific work of David LewisWilliams is distinctive for its profound role in shaping ideas of Bushman potency. See for example Lewis-Williams and Thomas Dowson (1989) and Lewis-Williams and Pearce (2004).

${ }^{2}$ In linguistic contexts Khoe is shorthand for speakers of Khoekhoegowab, the language principally of the Damara, Nama and Hai//om but also of Naro, some !Xun and $\neq$ Khomani. I use the term KhoeSān in the same sense as the older European construction of 'Khoisan', but have adopted the modern more phonetically accurate Khoe spelling (pronounced 'Khoi' with an added inflection 'ee'). I have capitalized the S of 'san' to reflect concerns over equality. I have accented the 'a', becoming 'ā', to pursue further phonetic accuracy, and rejected the hyphen sometimes used (Khoe-San) to emphasize the continuities between these groups and the validity of thinking in terms of KhoeSān regional culture.

(C) International African Institute 2011 
fieldwork amongst Nama, Damara and Topnaar - all 'Khoekhoe' - and Hai//om, !Xun, Ju/'hoansi, Naro and $\neq$ Khomani Bushmen. Fieldwork was carried out primarily in 2000 and 2007.

Within the so-called 'Kalahari debate', revisionist academics have been highly critical of scholars who identify both a persistent role for the environment in modern KhoeSān life and continuities between KhoeSān and their ancestors, separated by considerable time and possibly thousands of miles. ${ }^{3}$ I am aware that linking KhoeSān to the environment as I do in this analysis lands me in controversial territory. However, my historical comparative perspective strongly suggests the presence of continuities across time and space which seem intimately related to persistent ways of being in particular environments (Low 2008a) - an argument long established in other intellectual contexts (Dubos 1976). Although KhoeSān lifestyles are undoubtedly becoming more urbanized, change should not be assumed to work at the same rate in all cultural corners. Moreover, certain aspects of KhoeSān culture, particularly including dance and folklore, seem to negotiate change in ways evolved in the unpredictability of a huntergatherer lifestyle (Barnard 2002; Biesele 1993; Katz et al. 1997). My findings particularly resonate with Biesele's idea of a persistent hunter-gatherer 'imaginative substrate' - a hunter-gatherer way of thinking that continues to operate in lifestyles increasingly removed from hunter-gathering (Biesele 1993: 13). Critics of ideas of persistent and widespread KhoeSān culture would do well to reflect upon the longevity, breadth and persistence of the regional healing systems academics have identified amongst Bantu speakers (Feierman 2006; Janzen 1992; Pryns 1992; Schoenbrun 1998).

Despite the rich hermeneutic terrain birds represent, they have received little attention in Bushmen anthropology and virtually none in studies focused on the Nama and Damara. ${ }^{4}$ There is however sufficient material to enable comparative analysis when my medically orientated findings are buttressed by wider work on animal relationships and resource use. Not surprisingly, pulling the evidence together reveals variations in knowledge, belief and use, but at the same time it points to a strong continuity in fundamental ways of thinking about and working with birds. In the following I frame this commonality within ideas of 'potency', 'ownership' and 'working' with animals which I locate not within ideas of Bushman magic but as part of distinctive ways of thinking and doing.

Bushman rock art, /Xam texts, and KhoeSān folklore studies all highlight a magical context for birds set within a magical reality. In rock art, birds are not commonplace but the context of bird motifs, notably including ostriches, swifts and vultures, is often strongly suggestive of wider magical associations. Like other animals some birds appear linked to human or animal motifs by what have been interpreted as lines of potency or 'supernatural power' or 'magic force' (Garlake 1995: 102; Woodhouse 1992: 73). Other motifs include half-human, half-animal (therianthropic) forms that fit within a range of related beliefs about shamanic visions, rain animals and ritual initiatives to bring rain, which are central to historical /Xam shamanism.

\footnotetext{
${ }^{3}$ For the recent face of this debate see Wilmsen (2009). For a summary see Barnard (1992).

${ }^{4}$ Schapera (1930) provides a useful summary of the colonial bird literature.
} 
The /Xam archive includes many references to birds, ranging from hamerkops to ostriches, and from crows to the //keri or locust bird that drives locusts into bushes. The birds move within an inchoate world in which animals, the veld, people and the elements are woven together into the 'doings of the hunting ground' (Riley 2007: 294). The archive presents a surprisingly contemporary-looking KhoeSān relationship with birds wherein close attention is paid to birdsong and behaviour. Birds act as informants and messengers, and unusual behaviour points to a bird being a 'sorcerer' or 'sorcerer's thing'. Riley envisages that /Xam hunting and gathering was performed in 'a common life that accepted the potency of all living things and saw magic all around' (ibid.).

Recent folklore research presents a similarly magical setting for birds. Although birds are not prominent relative to other animals, the ostrich and the kori bustard are of special salience to creation myths (Biesele 1993; Schmidt 1989). Much folklore emphasizes a notion of animals having special skills by which they are known, and many of the tales concern inversions of reality wherein animals and people transform or do inappropriate things.

The association of Bushman animal relationships with 'magic' and 'supernatural potency' is intriguing given the recognition that Bushmen do not separate the sacred from the profane (Katz 1982: 28). This suggests that the magic we are dealing with has an everyday quality. I contend that continued use of essentially fuzzy notions of magic and the word 'supernatural' obscures analysis and deflects the question about what it is exactly that lies behind ideas of potency. In the following I use birds to explore this hidden nature of potency and how it relates to everyday life. My analysis revolves around KhoeSān environmental relationships and ideas of cause and effect that reveal fundamental concepts of how the world is connected. The potency connections I identify around birds are equally at play in other 'magical' spheres, including the ethereal 'strings' that are thought to anchor Bushmen to life - the threads on which shaman travel; or forces linking hunting equipment and hunters to prey; or times of human birth linked to control of particular weather. Depending on their different characteristics, birds appear within this potent meshwork as animals with human-like characteristics - some of whom proffer portentous messages; are potent medicines or causes of sickness; or control the weather.

When one examines the wider picture of potency, ranging from my findings to potency amongst early twentieth-century Nama (Hoernle 1918: 69), and to the plethora of recent references within rock art research, it is evident that potency is not one thing. This polymorphous characteristic has been observed by academics. To date, however, the question of what exactly potency is, and how its magic relates to everyday life, has barely been asked. Marshall's reflections on matters of !Kung (Ju/'hoan) potency - including sorcery; n/um, the protective or sicknesscausing force; and $n ! o w$, an ability to control the weather - remain perhaps the most explicit analysis. By her own admission Marshall struggled with the material and immaterial nature of $n / u m$, and how it related to other magical forces (Marshall 1999: xxxv, 236). In her earlier analysis she likened the phenomenon to 'electricity' (Marshall 1969: 351). I propose that we can develop our understanding of KhoeSān potency by borrowing from analysis of Polynesian mana. We should think of potency not as a thing but as the ability to make things happen. 
Thinking about birds and potency alerts us to pan-KhoeSān ways of working in the world. It steers potency out of the magical domain and into internally cohesive KhoeSān ways of being. The relationship of birds to KhoeSān reveals a way of thinking, or rationale, rooted in experience and lifestyle. It alerts us to a range of important issues, including a need to think carefully about the old anthropological problem of 'being' and 'being like' and the hegemonic implications of inserting metaphors where other sorts of relationship might exist. The prophetic reading of birds or mysterious medicinal use of birds is not esoteric. It comes from the same stable of ideas, experiences and ways of working that underlie other domains of KhoeSān knowledge, some of which are thought pragmatic because they are in accord with scientific beliefs about the world.

Anthropologists reveal that Bushmen know much about birds. Sugawara's finding of 68 names for 76 bird species amongst the /Gui and /Gana gives a good indication of similar species knowledge amongst Ju/'hoansi, !Xóõ and Naro (Blurton Jones and Konner 1976; Sugawara 2001: 71; Heinz 1978; Guenther, personal communication). Given that birds are a relatively unimportant food source, such detailed knowledge might be thought surprising. What it points to, however, are habits of perception rooted in a world in which all manner of signs are noted and learnt as indicators of what is happening in the environment. Reading the environment, or more accurately somatic listening to it, is a huntergatherer and KhoeSān way of gathering knowledge and understanding. Ingold (2000), Radin (1927) and Brody (1983) present similar accounts of huntergatherers as participants in a world that shines with signs and meanings. In Bushmen contexts Sugawara and Biesele have both examined how diverse Bushman beliefs are tied to adaptive behaviour. Throwing further light on KhoeSān environmental relationships, Biesele identifies Ju/'hoan folktales as carrying and sharing mechanisms of adaptive knowledge (Biesele 1993: 43).

One key towards understanding potency therefore lies in recognizing how KhoeSān are attentive to their environment, in a manner reminiscent of Gibson's 'education of attention' (Gibson 1986). A second lies in appreciating not just the gathering of knowledge but how knowledge works. As Dentan observed in his consideration of Semai bird knowledge, KhoeSān knowledge is memorate and informal (Dentan 2006: 297). It is experiential, personal and flexible - not fixed, authoritative and dogmatic. These dimensions of knowledge are particularly important when one reflects on the nature of potency. They are also ably emphasized in KhoeSān bird-naming habits, where the informality of knowledge, the extent of KhoeSān familiarity with the environment and the particularly engaging nature of birds all come to the fore.

Sugawara found amongst the /Gui that the form and nature of birds plays a far greater role in their naming than it does amongst mammals. About 40 per cent of the analysable lexemes in bird names denote bird song and 45 per cent colour, morphology and habits (Sugawara 2001: 71). This distinctive use of onomatopoeia or formal and behavioural characteristics as the pegs on which names and knowledge hang is found amongst not only the /Gui and /Gana but broadly across the KhoeSān. Amongst Damara, for instance, birds named after their sound include koko, the yellow billed hornbill; koeb, the grey lourie; and folob, the Namaqua dove. The !huib is also casually known as kai lanis, meaning 'big bird', and a bird which appears around rain time as Inanu anib, meaning 'rain bird'. 
In hunter-gatherer contexts where people are habituated to listening to the environment it is not surprising that birds are so rich in meaning. Unlike other animals, the properties of their voice and flight imbue birds with special significance. Birds have particular ability to arrest attention by appearing from nowhere, chattering loudly, performing extraordinary singular or group aerobatics or simply hovering as lone indicators of life in empty land and skyscapes. In Southern Africa birds are taken to further remarkable extremes in the large form of ostriches and kori bustards, both of which are particularly significant to KhoeSān.

KhoeSān see and hear bird behaviour knowing that some birds impart particular messages. Alternatively, strange behaviour is noted which might be attributed to the bird being more than a bird, a dead person or 'shaman'; or it might be accounted for in terms of significant events later discovered, such as the death of a friend (cf. Sugawara 2001). Amongst Hai//om hearing the /lgauseb bird tells of approaching visitors and the sound of the /honess (owl) at night portends bad news. Also amongst Hai//om, a bird making an 'eeeah' sound outside a house is announcing a pregnancy kept secret by one of the young occupants, or pregnancy may be prevented by being followed by the oo IInāh bird. The /khai ah is a particularly important bird to some $\mathrm{Ju} /$ 'hoansi. It makes a pitiful noise if it is telling you something bad, like a relative has died. It makes a good sound if something good is going to happen, and warns you if something is near. These sorts of signs are mingled with others that it is tempting to distinguish as more reasonable, such as a hovering vulture telling of a meat supply or pied crows 'craw crawing' in a tree, indicating there is a lion beneath. Such awareness of birds frequently regulates the day's activities.

Amongst KhoeSān the behaviour of birds not only tells and foretells things, but is linked to events as a causal factor. The $\neq$ Khomani, like the /Xam of old, know that agama lizards can lift their heads and call the rain. The rain will follow from the direction in which the lizards look. If a pangolin makes a whistling sound some Ju/'hoansi know it is going to rain. Similarly, if the n!òro bird (threestreaked tchagra) is 'playing and whistling too much' Naro know that clouds will come and the rain will soon follow. These animals are linked as rain's things; they 'work with' the rain and are accordingly powerful or potent.

As Sugawara observes, /Gui ways of knowing the world throw together what has been inappropriately conceived of as separate rational and non-rational knowledge domains. To appreciate the KhoeSān ways of thinking revealed in the previous examples one must be careful to retain a composite movement from relationships with the world to knowledge gathering and use of that knowledge. Sugawara analyses similar /Gui and //Gana ideas by locating them within a habitus based on sensitive 'noticing' essential to the Bushmen's daily movement in the bush (Sugawara 2001: 95-6). Sugawara frames 'noticing' as 'scanning lines' that contribute to an elaborate cognitive map. Whilst this conveys something of how KhoeSān relate to their environment, it fails to capture the broader KhoeSān way of being 'sensible' - of being open and listening to feelings in the body, to dreams, to birds, animal tracks, stories and gossip. It is only when one grasps the full extent of KhoeSān ways of working with life that one can begin to appreciate the wider dimensions of potency and potent birds.

It is hard to overstress the link between potency and how KhoeSān think in straightforward terms of how the world is known to work, and how one works, or 
is potent, in the world. The idiom of work is closely tied to ownership and to taking on the characteristics and powers of something, or mastership. KhoeSān healers, old and new, describe how they own and work with particular animals or plant medicines. Similarly /Xam folklore reveals shamans who were owners of springbok. A Hai//om healer described the Ju/'hoansi as the people who 'own the lion' because they work with the lion. Birds that are strong do strong things. By taking on the potency of a strong bird a person can become strong and achieve the same things as the bird; they own the bird or work with the bird. Birds that fly before the rain are described as working with the rain or being owned by the rain.

Lévi-Strauss presents related ideas in his observation that Siberian peoples use a woodpecker's beak to cure toothache because 'there is a point of view from which a woodpecker's beak and a man's tooth can be seen as 'going together' (Lévi-Strauss 1996: 9). In a KhoeSān context this going together, or 'working together', does not come from some primitive unreasoning sponge-like ordering of the world, as Lévi-Strauss implies, but from habits of receptivity, acuity, perception and sensitivity that enable survival. Working effectively with the world requires what Sugawara identifies amongst the /Gui as !qañ, good sense. There is a similar $\neq$ Khomani idiom of 'doing things nicely', which flags an aesthetics of care, slowness, skill, thoughtfulness and respect.

In $2007 \mathrm{I}$ asked a Ju/'hoan man if the moon had potency, n/um. He replied: 'I was out walking the other night in the moonlight when a lion crossed the road, nearby, so yes, I suppose the moon could have n/um.' Potency is within something when it is thought of within contexts of it making things happen. Marshall (1969: 351) observed that potency is found in all manner of things, from medicine men, to the sun, falling stars, ostrich eggs, rain, redwing partridges, bees and honey. Contrary to key accounts of n/um, potency is not a thing, a supernatural force or energy, it is the ability of phenomena to do things of consequence. Seeing the lion held real possible consequences for the man. Drawing on a discursive consciousness, the moon became a thing of power but only in relation to the lion. In this contingent context the moon, like bees or falling stars in other contexts, is potent because things happen around it.

The Ju/'hoan idea of n/um has been readily connected to wider Bushman ideas of healing power, particularly Naro tsso (Guenther 1999: 189). My work amongst Damara, Hai//om and !Xun groups strongly suggests the idea extends further to a phenomenon called /gais (Low 2008a). A person with /gais is called a gainee and holds the power of their particular /gais to do particular things. Rain /gais confer a familial relationship with rain and an accompanying sense of control. Healing Igais allow one to heal. The idea of Igais is founded in two factors. First, an awareness that organisms have a life force or $\neq o a b$ (wind in Khoe), 'spirit'. Second, that the abilities or attributes of an organism can be passed to another through sharing of wind, which equates with smell, or by the casting of a shadow, or by consuming parts of an organism or rubbing parts on the body or into small cuts. /Gais, like n/um, are shared between healers by shooting of invisible arrows or rubbing it in. The idea of /gais overlaps very strongly with n/um and suggests a wider context for Bushman potency.

How the idea of potency relates to birds lies in the ability of some birds to make people ill by movement of their 'wind' or shadow. This explanation belongs to the same family of ideas as /gais, n/um, tsso and other potencies. Furthermore use of 
bird parts in medicine, or indeed any use of birds, holds in it the notion that the essence of the bird is at work and brings the qualities and strengths of the bird. To recognize a bird illness or the need for a bird medicine is to apply the knowledge of what a particular type of bird does or what happens around it.

\section{CREATION MYTHS AND OSTRICH MEDICINE}

Moving easily in and out of focus, between sky and earth, birds capture attention and bring messages from the past and future, from near and far. Like shamans, they move between earth and spirit. This is not perceived as a privileged movement across a veil to the spirit world, as rock art studies emphasize, but as everyday movement in an environment occasionally perfused with spirits and their influence (Lewis-Williams and Dowson 1990). KhoeSān cultures are not permeated with spirits although their presence and roles are acknowledged by all. A more salient characteristic is a knowledge that animals and people can transform. This openness to ideas of transformation is rooted in KhoeSān creation myths and strongly underscores ideas of potency.

Creation myths carry an ability of birds to move between mythical old time and new time, wherein old time equates to an old but still present spirit world. Change was the original force in the Bushman world (Guenther 1999; Biesele 1993; Keeney 2007: 240-55). At the time of First Creation it was the nature of all things to change over and over again and the original ancestors gave birth to creatures that kept changing into different animals. Then came Second Creation, a time of fixity when people and animals became separated from each other and the animals were named. Despite this cleavage, however, the two realms remain linked. Healers shapeshifting and transforming illness, tricksters inverting everyday life, birds moving across borders and animals being perceived as dead people, all attest to a continued role of First Creation in the present.

It is indicative of the special proximity of birds to matters of spirit that both the ostrich and the kori bustard lie at the heart of creation myths. Biesele has recorded $\mathrm{Ju} /$ 'hoan stories that linked the kori bustard (Ardeotis kori) ${ }^{5}$ with the primal formal differentiation of one animal from another. Biesele relates that the kori bustard is considered to be Kaoxa's servant and 'a kind of captain of the other animals'. Kaoxa is the divinity who 'calls any dance and was the one who made the fire of creation'. The Ju/'hoansi believe that animal characteristics were branded into animals using the fire of creation and the flames of the fire were fanned by the strong wings of the kori bustard. The branding day marked the end of the magical time of human and animal overlap (Biesele 1993: 23, 98).

A Hai//om story about the ostrich juggles similar themes of fire, large birds and branding although it does so as an explanation for ostrich characteristics.

The ostrich had a fire on which he cooked his food whilst the others ate food raw. One day he went to visit the people and they saw black spots on his legs. The people asked,

\footnotetext{
${ }^{5}$ I have identified birds with familiar and scientific names where possible. I only have KhoeSān names for a number of birds but I do not believe this detracts from the validity of the account; indeed using only KhoeSān names reinforces the message of different forms of knowledge that should not always be unthinkingly channelled into Western paradigms.
} 
'Where did you get those?' [burn marks]. The people said, 'We have to organize a dance together.' When they danced the ostrich hid the fire under his arms and didn't stretch his wings. The people asked him 'Why don't you stretch?' So he did and he forgot about the fire and a person stole it. The ostrich chased him and kicked the rock. That is why he only has three toes. (Elizabeth $\neq$ Naibeb)

In this brief story the ostrich is ontologically elevated above other animals; he eats his food cooked not raw. This echoes the previous account in which the kori bustard holds power as Kaoxa's servant. There is even a hint that the ostrich has fire before people. Amongst the Naro Guenther identified similar stories linking ostriches to the acquisition of fire. These typically featured a woman, or an Ostrich Woman, as custodian of the First Fire (Guenther 1999: 160). The fire holders kept the embers alight under their apron or wings. The Eastwoods similarly encountered a Naro belief in an Ostrich Woman, /Osê. /Osê is a magically potent bird who lives in the "branches of the "red-heart acacia"'. She is particularly dangerous to children and visible only to shamans. As the Eastwoods note, a potent status of the ostrich was further found in /Xam belief. A /Xam Bushman named the ostrich 'Magic Bird' and observed: 'With the exception of the Moon and the Male Ostrich, all other things mortal are said to die outright, and not come to life again' (Eastwood and Eastwood 2006: 108).

Folktales both inform and reflect what ostriches mean to KhoeSān. Medicinal use of the ostrich is founded in myth and experience of the ostrich, set against knowledge that potency can move. The danger of /Osê to children speaks of a shamanic potency rooted in the ostrich's place in creation stories and its immortal associations. Living beyond the normal cycle of birth and death ties ostriches to First Order creation. Immortality links the ostrich to the trickster's characteristic of perpetual life despite, or because of, an ability to transform, like the cycles of the moon and sun. At a basic level, contemporary KhoeSān accept this knowledge because they know that the ostrich is an exceptionally strong animal. The ostrich, like the kudu, very seldom gets sick. The Damara praise the way it jumps hunting nets. It is well known that an ostrich, though it appears to have been killed, will get up and run.

The use of ostrich parts in medicine lies in knowledge of what ostriches are known to do and be, mediated by folklore and memorate knowledge habits. Medical praxis is in turn dependent upon the fundamental KhoeSān belief in the possibility of transference of formal qualities between animals and people. By wearing, sniffing, eating and rubbing on animals parts, people become owners of particular animal strengths or abilities. This complex of ideas holds the key to understanding the use of ostrich dung, ostrich eggs in powder or bead form, and ostrich leg tendons as necklaces and ties around parts of the body.

Across the KhoeSān ostrich eggshell is used in healing contexts, either as beads or as a burnt and ground powder to be rubbed on the body or swallowed. All groups ascribed healing benefit to wearing ostrich eggshell beads. Often eggshell beads are worn by babies around the neck or waist to 'make them strong'. It makes them strong because they become owners of ostrich potency. Naro, Hai//om and !Xun used eggshell or leg tendon necklaces if a baby's neck is 'too flexible' or painful, and beads around the waist for diarrhoea. Often KhoeSān combine wearing an eggshell necklace with drinking burnt and ground ostrich eggshell as part of a treatment for a set of infantile sickness signs and symptoms, referred to simply as 'children's sickness' or lgôaron /lob amongst Damara. 
Children's sickness usually refers to a combination of fever, diarrhoea and stomach pain, or to signs that equate to acute dehydration or meningitis typically including cessation of movement of the skin over the anterior fontanel, and rigidity of a baby's body, possibly accompanied by spastic paralysis.

Both the formal characteristics of the ostrich and ostrich behaviour play out in the different sorts of medicine. The use of eggshell for children with fever seems to draw on a rich set of subconscious ideas linking fear of the hot sun and death with coolness and health. The ostrich is remarkable for sitting on its eggs to keep them cool in extraordinary temperatures. Providing ostrich eggshell for fever is accordingly to bestow the cooling potency of the ostrich.

The legs and neck of the ostrich are highly distinctive amongst Southern African animals. The long bald legs have a familiar, if aberrant, human quality. Like the neck, what is also overtly apparent in the legs is their strength. The qualities of the strong legs or neck are transferred to KhoeSān by wearing or eating parts of the ostrich. These confer body strength in general, but neck strength and leg strength in particular. Amongst the Damara the tendon of an ostrich leg is used to treat knee or leg pain, $\neq$ gurub. ${ }^{6}$ The tendon is tied variously around the knee and ankle or down between the two, alongside the tibia. This paralleling of ostrich leg tendon to a human leg infirmity strongly supports an idea of transference of qualities that is similarly played out when ostrich medicine is used for the loose necks of children - although in the latter case ostrich neck is not used, as might be expected. Using a part not from the neck indicates how one part of an animal is conceptualized as holding the potency of the entire animal. The knowledge expressed by one Naro Bushman when he said that if you eat the kori bustard you will never sit down further demonstrates how one part of an animal can hold and convey the behavioural and physical characteristics of the whole animal - in this case its long-legged ambulatory habits.

Across the KhoeSān run ideas of people being introduced to powerful phenomena through minor or major rituals of controlled exposure. This applies to puberty rites or even how to introduce oneself to a new physical environment or weather phenomenon including rain (Marshall 1999: 124-6). Amongst the Nama I encountered a notion that further locates ostriches in the formative cosmological process of becoming part of the physical world, or second order creation in Ju/'hoan terms. When a baby is born some Nama say 'he doesn't know anything' and for a small number of days, they place a little burnt and ground ostrich eggshell on the tongue of the newborn as a 'medicine', called !huitsa. This medicine is 'just to teach the child. It is the first thing that comes to his mouth.' The wider context of the word !huitsa relates to !hui, variously meaning bursting open, exploding, opening of a spring and bursting into blossom (Haacke and Eiseb 2002: 337) - all of which juggle this idea of coming forth into creation.

From the late nineteenth century the philologist Hahn provides yet another clue as to the possible potency of the ostrich. Hahn identified !Urisis as the name of the sun, meaning 'the white one'. Hahn determined that the root of !Urisis

\footnotetext{
${ }^{6}$ Possibly related to $\neq$ khurub, meaning blood vessel, or !Khuru, kneecap (Haacke and Eiseb 2002: 572). The illness refers to a !nu or lump in the medial hamstring tendon associated with a bent, stiff and painful leg.
} 
lay in ' $\bar{u}$ which, as amongst the !Ai Bushmen, originally meant 'white' and 'egg'. And 'it is not unlikely', Hahn proposed, that the sun, which is round and white, was equated by at least Khoikhoi, if not Bushmen, to the ostrich's 'egg par excellence' (Hahn 1881: 141). A $\neq$ Khomani Bushmen indicated a further dimension of this link by observing that ostrich eggs often sparkle or shine in the bush. $^{7}$

The transformative and potent properties of the rising and falling moon are a central pole in KhoeSān folklore as is, less prominently, the sun - the revered and feared bringer of daylight from the East, the wife of the Khoekhoe trickster figure Haitsi-Aibeb (Hahn 1881: 141) and the Ju/'hoan n/um-filled 'death thing' (Marshall 1969: 352). Associations of rebirth and extreme potency lie at the heart of Keeney's observation that, amongst the Ju/'hoansi, the most special dream a healer could have is of an ostrich eggshell cracking open, meaning the 'rope of light that goes to the Big God is now open for you'. In a related sense some Ju/'hoansi believe that really strong healers do not just see coloured threads tracing round the sky when they are dancing, but they see these ropes as ostrich eggshell beads. Each bead is a step up the rope to the ancestors and the Big God (Keeney 2003: 42, 60). Giving children ostrich eggshell medicine reflects associations of the ostrich with strength but also with coming into creation and having strength in the cycle of life and death. In an extension of this belief, the same idea is used for the ultimate divine gift to the strongest healers, an opening up to the essence of creation. There is a sense in which the cracking of the eggshell is a rebirth into the divinity of First Order creation.

Since the mythical branding, animals and people have been different. However, the continual influence of First Order creation means that in certain situations humans and animals merge again. Conceptually there seems a hierarchy of merging. There is the great merging wherein Bushmen healers become part of the Big God and there is a less powerful shamanic merging with animals that works with the same sympathies but is more a part of everyday medicine. Merging is graphically represented in the part-human, part-animal therianthropes of Bushman rock art. Other forms of merging include KhoeSān healers' shapeshifting.

Ideas of people transforming into animals have been recorded amongst the KhoeSān since the earliest colonial records (Schapera 1933: 213). Accounts of the Cape /Xam reveal that sorcerers shifted into all sorts of animals, including lions, birds and jackals, and that animals could similarly shift into human form. ${ }^{8}$ In current contexts, Bushmen healers are particularly known for their ability to change into lions. In lion form they can frighten or kill people and animals or travel far to check out distant happenings. The ability to transform is intrinsic to the First Order trickster figures of KhoeSān belief, who sometimes appear as animals and can be recognized by their exceptional behaviour, such as not dying when shot.

\footnotetext{
${ }^{7}$ This maybe associated with an idea widespread at least in the southern Kalahari that diamonds can be retrieved from the stomach or throat of ostriches or possibly from ostrich dung.

${ }^{8}$ From an electronic copy of the Bleek archive included in Skotnes (2007: BC 151 A2 1063 ).
} 
The KhoeSān idea of transformation between people and animals is a Second Order creation phenomenon that demonstrates the continued power of the trickster. At the same time, people and animals being the same is a First Order phenomenon and hence transformation serves as a direct link to the past. In this manner animal forms allow dead people to have a role in the present. WagnerRobertz recorded a typical example of this in the case of an elderly half-Bushman, half-Damara man, Frederik!Gaeb, who was told by his father shortly before he died, 'If you see a big bird in the morning then you must know that I am coming for you.' Frederik had seen his dead father numerous times in the forms of both a snake and a bird. ${ }^{9}$

A further idea closely related to transformation concerns animals entering people and causing sickness. Some /Xam, for instance, attributed sickness to owls and butterflies (Hewitt 1986: 292). The miniature animals inside people are typically removed in a healing dance by 'sucking', 'snoring' or 'pulling', which is performed by a healer rubbing his hands or head, or inhaling with his nose or mouth, on a patient. The miniature animal enters the healer and is then expelled, usually by coughing or snorting. An elderly Damara lady described how, at one point of her life, she was persistently sick; she could not feel anything and did not sleep, sitting up all night. One day a man came to help her. He told her she had a bird and a snake inside her. Although he could not suck the snake out, he sucked out the bird. It was a real bird. The man showed it to her and then threw it in the fire. From that day on she was better.

\section{BIRDS AND WIND}

Amongst the KhoeSān ideas of wind serve as a key way of talking about how essence or potency moves between organisms and other natural phenomena (Low 2008b). A well-known cause of sickness amongst babies is the shadow or wind of a bird passing over the head of a baby. The potent wind penetrates the baby and causes depression of the anterior fontanel. Some say the baby's limbs claw up like the talons of a bird. The Hai//om call the bird a //gori (a kite?). The name probably relates to //gorob, meaning the talon of a bird of prey (Haacke and Eiseb 2002: 257). The bird is therefore named by what it represents. To protect children from the sickness-causing shadow of the Ilgauwa ha bird, Ju/'hoansi string ostrich beads around their waists.

The way wind relates to life, death and birds is both rich and complex. Approaching the topic from an academic perspective, it is tempting to try and explain what appear to be jumbled ideas by untangling them into metaphor, symbolism, allegory, metonymy, synecdoche or some other analytical abstraction. Although such analysis can be highly insightful it holds the danger of perpetuating an interpretative colonialism within which KhoeSān phenomena are not taken on their own terms and granted an equal reality. In this translation there lies the danger that something highly informative about how KhoeSān work and

\footnotetext{
${ }^{9} \mathrm{MS} 52$ from the unpublished manuscripts of the late Dagmer Wagner-Robertz, consulted in 2000 with kind permission from her husband. The manuscript was held by Wilfred Haacke at the University of Namibia.
} 
think is being lost. In Western terms, if one does something with or to something that is not the source phenomenon but is symbolically, metaphorically or otherwise related, in conventional terms one is not doing something with the source phenomenon. But in a KhoeSān context the depth and profundity of the relationship between a bird, a child, and the wind of the bird is such that real implications and effects manifest in the child by 'working with' either of the interrelated entities.

In the context of birds the notion of potent wind is more involuted and complex still. Amongst KhoeSān the experiential knowledge of birds' wind-beating wings entangles with broader ideas about wind and potency. Awareness of wind generated by wings seems to have contributed to concepts of birds actually being the wind, an idea further indicated by the awareness that birds come and go through the air. In a /Xam story, wind, who was formerly a man, became a bird who lived in a hole in the mountains and ventured out for food. ${ }^{10}$ A similarly intimate linking between the blowing of the wind and birds is echoed in something a psychologist, Porteus, described in 1937. Porteus wrote that Bushmen thought of the wind rushing across the veld as 'a huge bird that is the forerunner of death. It cannot be seen but the beat of its wings can be felt as it passes by' (Porteus 1937: 119). Such an account of wind's origin is in keeping with KhoeSān ways of thinking, particularly because it vividly links birds, wind and sickness. In current contexts wind blowing in from foreign parts is sometimes thought to be the cause of illness as, in a related sense, is the wind coming in from foreign or 'unknown' people (Low 2008a: 263).

These sorts of complex beliefs inform KhoeSān action in ways that do not make sense if we only think in terms of metaphor. In an historical /Xam context, for example, //Goo-ka-!kui, or 'Smoke's Man' ('owner of' or 'worker with' smoke) saw a !kuerre!kuerre bird at the Haartfontein Mountains and threw a stone at it, based on his understanding that it was the wind. The wind bird thereupon went into a hole in the mountain and the wind blew so frighteningly hard that the Bushmen went home (Bank 2006: 149; Bleek 1911: 107). Throwing a stone at the bird is working with one side of the equation and it has an effect on the whole; the wind blew.

KhoeSān agency intersects with the world at a point where one thing is experienced as being connected to another, given the overall context and outcome. In the late nineteenth century Hahn observed that 'Khoi Khoi' caught $a \neq g a$ /lgoeb bird (a nightjar), burnt it to ashes and scattered it about to produce clouds and rain (Schapera 1930: 391). This behaviour is understandable when one thinks of nightjars in a context of working with or being 'of the rain'. Nightjars are usually nocturnal feeders on insects. Their activity levels could well be associated with rain in terms of rain-wind bringing insects, insects gathering in numbers after rain, or the darkening of a storm encouraging nightjars to emerge. Hollman has similarly linked the comments of /Xam Bushmen concerning swallows, or possibly swifts, being 'rain's things' to their increased activity around storm times. He adds that the physical attributes and behaviour of swifts presented a 'package' of characteristics that associated them in the minds of Bushmen with shamanism, healing dances and altered states of consciousness.

\footnotetext{
${ }^{10}$ From an electronic copy of the Bleek archive included in Skotnes (2007: BC 151 A2 1083 ).
} 
And he suggests that this resonance, coupled with the explicit identification of swift-people as 'rain-sorcerers' by a /Xam Bushman, /Han $\neq$ Kasso, accounts for the representation of swift-people as potent motifs in Bushman rock art (Hollman 2005: 25).

Ethology, the scientific study of animal behaviour, is highly useful for interpretation of the /Xam world, but to understand KhoeSān animal and spirit relations one must be open to events and behaviour being connected in possibly unfamiliar ways. A baby which adopts the posture of a bird if the bird's shadow or wind passes over its head is one example of how observation, or 'listening to the environment' and making connections between phenomena, informs KhoeSān practice. A similar example is evident if Hai//om children eat pangolin; the child will die and its body take the form of the pangolin, meaning its arms will curl forwards. Some Hai//om believe a child that makes a coughing sound like the noise of the //gores bird becomes sick by having the bird, or the bird's wind, $\neq o a b$, in them. This sort of ownership of a bird indicates a potency that is too strong to the point of danger. Köhler describes a similar phenomenon amongst the Khoe. The Khoe believe certain animals, including lion, duiker and bushdove, can cause sickness. They are said to /l'oź a person, which literally means 'coming down' (Köhler 1971: 318). The phrase seems particularly appropriate to bird relationships. Not only can birds passing overhead cause sickness but, at least amongst the Hai//om, so too can simply passing under the nest of the !nanas bird.

The notion of birds causing sickness is very widespread amongst the KhoeSān and probably has a considerably wider range amongst their African neighbours. $\mathrm{A} \neq$ Khomani Bushman, Habijol, for instance, knew that one must never kill the koring or corn bird because 'when the air goes out of the bird it takes your air out with it, and then you will die'. The considerable variety of ideas that exists about bird sickness indicates the flexible way in which knowledge is held and operated. Hai//om refer to the shadow of the red-tailed //go-ās as the cause of a baby's sickness whilst Ju/'hoansi attribute bird-shadow sickness variously to the Subbah (Tsaba), possibly an eagle, or the //gam. In line with the idea of an animal entering a person some Ju/hoansi thought such baby sickness was caused by the bird 'shouting' over the baby, thereby putting its body into the baby and causing the baby to grow feathers. Conversely !Xun and Naro spoke of child sickness being caused by the /gou (in !Xun) taking the child's heart. This idiom is one heard more commonly in healing dance contexts when some healers speak of having to rescue the heart of the sick person from the spirit realm.

\section{CONCLUSION}

Qualities of 'talking' and flying distinguish birds from other animals. Birds arrest attention and fly into sociality. Birds hop about as you perform household chores or sit and talk nearby. Flocks of birds swirl in giddy displays, landing and then ascending with a whoosh on the turn of your head or the roar of a car. A noisy bird might sit in a tree 'cawing' over your baby or its black shadow might trace across the baby's head - something remembered as the baby becomes ill the following day. Or birds might be seen as pinpoints in an empty sky over sunbaked plains, moving on the borders of the knowable. 
At different times and places a shifting range of animals feature within accounts of KhoeSān life. Along with eland, lions, elephants and snakes, birds are particularly meaningful animals. Their characteristics lend them a quality of straddling the border between people and animals, and their portentous messages, and presence or absence, play with time and ideas of coming from other spaces. Thinking about birds in contexts of potency draws out fundamental KhoeSān ideas, as relevant to the hunting ground of the /Xam as the village of modern KhoeSān, and in all likelihood of considerable pertinence to the elusive therianthropes and 'magical lines' of ancient rock art. When one expands the general bird category to encompass ostriches the emphasis shifts to the perceived qualities of ostriches, including their remarkable health, strong legs and neck, egg-sitting habits, and the sun-like shimmer of the eggshell. The way bird shadow, sounds, body form and feathers enter babies highlights the widespread belief that an animal's or person's essence, which holds their abilities, can move into other organisms; the healer can move into the lion and a dead person into a bird. Thinking about ostriches leads one to creation, to the most widespread KhoeSān medicine, ostrich eggshell, and ideas of physical and spiritual growth. Reflection on medicine as an agent of transformation suggests a need for rethinking what we mean by jewellery and personal enhancement. Ostrich necklaces are one of the oldest artefacts of Bushmen ancestors and perhaps the most common contemporary body adornment of Bushmen. Like perfume, jewellery is a personal enhancement that changes the sphere of immediate relations. It has a transformative capacity of attraction or repulsion and is, in this sense, potent. In a similar vein, where parts of birds are used in different circumstances, ranging from tools to the accoutrements of a healer, the general background knowledge of birds feeds into the multiple meanings of the object.

The potency that surrounds birds is not a thing that KhoeSān explain in a clearly defined and systematic manner. It is an analytical abstraction of a set of things talked about or depicted in different ways at different times. Keesing reminds us that finding cohesive systematic knowledge where none exists is always a danger and this is particularly so amongst people like the KhoeSān whose knowledge is characteristically memorate and flexible (Keesing 1985: 202). Using the term potency is like trawling a net across diverse sources and the dredged thoughts of KhoeSān individuals from disparate contexts. Wherever the net is swept, however, similar and distinct ways of thinking become visible enough to talk about potency in a cohesive manner.

What seems warranted is to recognize a role for potency but not to pin it down as an abstract noun. Potency is medicine, it is danger, it is liminality and the place of significant change. It is Inum, Igais and wind, $\neq 0 a b$. It is the breath of life manifest in a form which carries its properties to another. It is the control of clouds by a lizard or bird, the control of a /Xam sorcerer over 'his' or 'her' game animals, or the ability of an elderly Damara woman to pole-axe a dassie with her pointing finger. Echoing Ingold's assertion that the fine-tuning of perception found amongst hunter-gatherers is best understood as a process of enskillment (Ingold 1996: 40), potency comes out of an aesthetics of care; care in listening and recognizing potency but also in acting in the world and working with potency. Although there are indications, like mana, that social change can commoditize potency, potency remains best considered as a verb. What Keesing observes of mana is highly pertinent to potency. 'Things that are mana are efficacious, potent, 
successful, true, realized: they "work". Mana is not 'an invisible spiritual substance or medium' (Keesing 1984: 138).

The KhoeSān demonstrate a proclivity for observing the normal and abnormal, and linking each to a range of phenomena including weather events, social encounters, illness or hunting activities. A lizard on a gatepost indicates meat might be given at a person's hut. A tingling on the back of the thighs tells a person that someone close to them is visiting in a car. These are the same sorts of listening habits that are visible in bird messages and 'presentiments' or the 'sympathetic' feelings connecting /Xam Bushmen to the animals they hunt, or the burning forehead pain !Xõ experience on the hunt (Liebenberg 2001: 93). Where potency loses its power is in the insertion of metaphor.

Analysis through metaphor has been essential to shamanistic interpretations of rock art. We are told that crabs, for instance, are metaphors for the immersive feeling of trance; eland for the trance death of a shaman, elephants for rain and fat for sex (Deacon 1988: 135; Lewis-Williams 1981: 48; 2001: 28). Whilst these motifs are explicitly recognized as images of power, the power is not, however, necessarily related to shamanic life across the veil. KhoeSān participation in life is about establishing truths and working with the world. Metaphors for KhoeSān are expressions of real family unities, ownership and possession of the same wind and abilities. By locating these images of power in the shamanic realm, amongst workings across the veil, one risks losing something of the everyday role of metaphor and KhoeSān awareness that potency moves in hunting and other everyday life events. Not just shamans but all KhoeSān work with metaphor.

Metaphor is a slippery slope within which ethnographers move from the recognition of real relational unities, as Ingold recognizes them, to figurative likeness (Ingold 1994: xxiv). Berman observes that amongst hunter-gatherers 'experience and metaphor unite in a joint concern to know and use the truth' (Berman 2000: 292). But as Lakoff and Johnson recognize, metaphors are not distinct from experience but rooted in it (Lakoff and Johnson 1980: 19). Metaphors do not provide a means of connecting together 'objects, events and actions that appear to be empirically (factually) disparate and unconnected', as Tilley suggests (Tilley et al. 2006: 8). At least for KhoeSān they are simply statements about connection, absolutely founded in experience. As Ingold observes, the accomplished hunter consults the world, not representations in his head (Ingold 1996: 41).

In a study of nomadic spirituality, Berman located the magical world of huntergatherers in the magic of everyday life (2000: 12). Everyday life is magical for the KhoeSān but not in the way ethnography frequently suggests. The magic is the wonderful way in which the world works, revealed by interest in its meaning and recognized for the consequences it may hold and the opportunities it offers.

\section{ACKNOWLEDGEMENTS}

I am extremely grateful to the anonymous reviewers and other members of the KhoeSān research community who have offered encouragement alongside highly valuable, informed and constructive criticisms of earlier drafts of this article. And I am greatly indebted to the Economic and Social Research Council for their support of the DPhil and the subsequent research project which underlie this work. 


\section{REFERENCES}

Bank, A. (2006) Bushmen in a Victorian World: the remarkable story of the Bleek-Lloyd collection of Bushman folklore. Cape Town: Double Storey Books.

Barnard, A. (1992) 'The Kalahari debate: a bibliographic essay', Occasional Papers 35, Centre of African Studies, University of Edinburgh.

_ (2002) 'The foraging mode of thought' in H. Stewart, A. Barnard and K. Omura (eds), Self- and Other-Images of Hunter-Gatherers, Senri Ethnological Studies 60. Osaka: National Museum of Ethnology.

Berman, M. (2000) Wandering God: a study of nomadic spirituality. Albany NY: State University of New York Press.

Biesele, M. (1993) Women Like Meat: the folklore and foraging ideology of the Kalahari Jul'hoan. Bloomington and Indianapolis IN: Indiana University Press.

Bleek, W. H. (1911) Specimens of Bushman Folklore Collected by the late W. H. I. Bleek and L. C. Lloyd. London: George Allen and Company.

Blurton Jones, N. and M. J. Konner (1976) '!Kung knowledge of animal behaviour (or: The proper study of mankind is animals)' in R. Lee and I. de Vore (eds), Kalahari Hunter-Gatherers: studies of the !Kung San and their neighbours. Cambridge MA and London: Harvard University Press.

Brody, H. (1983) Maps and Dreams: a journey into the lives and lands of the Beaver Indians of northwest Canada. Harmondsworth: Penguin.

Deacon, J. (1988) 'The power of a place in understanding southern San rock engravings', World Archaeology 20 (1): 129-40.

Dentan, R. K. (2006) 'How the androgynous bird god brought agriculture to Semai of west Malaysia' in P. Le Roux and B. Sellato (eds), Divine Messengers: bird symbolism and aesthetics in Southeast Asia. Marseille: Connaissances et Savoirs/Seven Orients/IRASEC/Maison Asie Pacifique (CNRS et Université de Provence).

Dubos, R. (1976) A God Within: a positive view of mankind's future. Abacus: London.

Eastwood, E. and C. Eastwood (2006) Capturing the Spoor: an exploration of Southern African rock art. Cape Town: David Philip.

Feierman, S. (2006) 'Afterword: ethnographic regions - healing, power and history' in T. J. Luedke and H. G. West (eds), Borders and Healers: brokering therapeutic resources in southeast Africa. Bloomington and Indianapolis IN: Indiana University Press.

Garlake, P. (1995) The Hunter's Vision: the prehistoric art of Zimbabwe. Seattle WA: University of Washington Press.

Gibson, J. J. (1986) The Ecological Approach to Visual Perception. Ithaca NY: Cornell University Press.

Guenther, M. (1999) Tricksters and Trancers: Bushman religion and society. Bloomington and Indianapolis IN: Indiana University Press.

Haacke, W. H. G. and E. Eiseb (2002) A Khoekhoegowab Dictionary with an English-Khoekhoegowab Index. Windhoek: Gamsberg Macmillan.

Hahn, T. (1881) Tsuni-//Goam: the supreme being of the Khoi-Khoi. London: Trübner and Co. 
Heinz, H. J. (1978) 'The Bushman's store of scientific knowledge' in P. V. Tobias (ed.), The Bushmen: San hunters and herders of Southern Africa. Cape Town: Human and Rousseau.

Hewitt, R. L. (1986) Structure, Meaning and Ritual in the Narratives of the Southern San. Hamburg: Helmut Buske Verlag.

Hoernlé, A. W. (1918) 'Certain rites of transition and the conception of !Nau among the Hottentots', Harvard African Studies 2: 65-82.

Hollman, J. C. (2005) "Swift-People": therianthropes and bird symbolism in hunter-gatherer rock-paintings, Western and Eastern Cape Provinces, South Africa', South African Archaeological Society Goodwin Series 9: 21-33.

Ingold, T. (1996) 'The optimal forager and economic man' in P. Descola and G. Palsson (eds), Nature and Society: anthropological perspectives. London: Routledge.

- (2000) The Perception of the Environment: essays in livelihood, dwelling and skill. London and New York NY: Routledge.

Ingold, T. (ed.) (1994) What Is an Animal? New York NY: Routledge.

Janzen, J. (1992) Ngoma: discourses of healing in Central and Southern Africa. Berkeley CA: University of California Press.

Katz, R. (1982) Boiling Energy: community healing among the Kalahari Kung. Cambridge MA: Harvard University Press.

Katz, R., M. Biesele and V. St Denis (1997) Healing Makes Our Hearts Happy: spirituality and cultural transformation among the Kalahari Jul'hoansi. Rochester VT: Inner Traditions.

Keeney, B. (2003) Ropes to God: experiencing the Bushman spiritual universe. Philadelphia PA: Ringing Rocks Press.

(2007) Shaking Medicine: the healing power of ecstatic movement. Rochester VT: Destiny Books.

Keesing, R. M. (1984) 'Rethinking "Mana"', Journal of Anthropological Research 40 (1): 137-56.

— (1985) 'Conventional metaphors and anthropological metaphysics: the problematic of cultural translation', Journal of Anthropological Research 41 (2): 201-17.

Köhler, O. (1971) 'Die Krankheit im Denken der Kxoe-Buschmänner' in Veronika Six et al. (eds), Afrikanische Sprachen und Kulturen - ein Querschnitt. Hamburg: Deutsches Institut für Afrika-Forschung.

Lakoff, G. and M. Johnson (1980) Metaphors We Live By. Chicago IL and London: University of Chicago Press.

Le Roux, P. and B. Sellato (eds) (2006) Divine Messengers: bird symbolism and aesthetics in Southeast Asia. Marseille: Connaissances et Savoirs/ Seven Orients/IRASEC/Maison Asie Pacifique (CNRS et Université de Provence).

Lévi-Strauss, C. (1996) The Savage Mind. Oxford: Oxford University Press.

Lewis-Williams, J. D. (1981) Believing and Seeing: symbolic meanings in southern San rock paintings. London and New York NY: Academic Press.

- (2001) 'Southern African shamanistic rock art in its social and cognitive context' in N. S. Price (ed.), The Archaeology of Shamanism. London: Routledge.

(2004) San Spirituality: roots, expressions and social consequences. Cape Town: Double Storey Books. 
Lewis-Williams, J. D. and T. Dowson (1989) Images of Power: understanding San rock art. Cape Town: Struik Publishers Ltd.

_ (1990) 'Through the Veil: San rock paintings and the rock face', South African Archaeological Bulletin 45 (151): 5-16.

Liebenberg, L. (2001) The Art of Tracking: the origin of science. Cape Town: David Philip.

Low, C. H. (2008a) Khoisan Medicine in History and Practice, Research in Khoisan Studies 20. Köln: Rüdiger Köppe Verlag.

- (2008b) 'Khoisan wind: hunting and healing' in E. Hsu and C. Low (eds), Wind, Life, Health: anthropological and historical perspectives. Oxford: Blackwell.

Marshall, L. (1969). 'The medicine dance of the !Kung Bushmen', Africa 39 (4): 347-81.

_ (1999) Nyae Nyae!Kung: beliefs and rites, Peabody Museum Monographs 8. Cambridge MA: Harvard University Press.

Porteus, S. D. (1937) Primitive Intelligence and Environment. New York NY: Macmillan.

Pryns, G. (1992) 'A modern history of Lozi therapeutics' in S. Feierman and J. Janzen (eds), The Social Basis of Health and Healing in Africa. Berkeley CA: University of California Press.

Radin, P. (1927) Primitive Man as Philosopher. New York NY and London: D. Appleton and Company.

Riley, E. (2007) 'The hunting ground's doings: /Xam narratives of hunting, animals and the veld' in P. Skotnes (ed.), Claim to the Country: the archive of Wilhelm Bleek and Lucy Lloyd. Athens OH: Ohio University Press.

Schapera, I. (1930) The Khoisan Peoples of South Africa: Bushmen and Hottentots. London: George Routledge and Sons Ltd.

- (1933) The Early Cape Hottentots. Cape Town: Van Riebeek Society.

Schmidt, S. (1989) Catalogue of the Khoisan Folktales of Southern Africa. Hamburg: Helmut Buske Verlag.

Schoenbrun, D. L. (1998) A Green Place a Good Place: agrarian change, gender and social identity in the Great Lakes region to the fifteenth century. Oxford: James Currey.

Skotnes, P. (ed.) (2007) Claim to the Country: the archives of Wilhelm Bleek and Lucy Lloyd. Athens OH: Ohio University Press.

Sugawara, K. (2001) 'Cognitive space concerning habitual thought and practice toward animals among the Central San (/Gui and //Gana): deictic/indirect cognition and prospective/retrospective intention', African Study Monographs, Supplement 27: 61-98.

Tidemann, S. and A. Gosler (eds) (2010) Ethno-Ornithology: birds, indigenous peoples, culture and society. London and Washington DC: Earthscan.

Tilley, C., W. Keane, S. Kuechler, M. Rowlands and P. Spyer (eds) (2006) Handbook of Material Culture. Thousand Oaks CA: Sage.

Wilmsen, E. N. (2009) 'To see ourselves as we need to see us: ethnography's primitive turn in the early Cold War years', Critical African Studies 1: 1-75.

Woodhouse, B. (1992) The Rain and Its Creatures: as the Bushmen painted them. Rivonia, South Africa: William Waterman Publications. 


\section{ABSTRACT}

It is not surprising that animals have played a significant role in KhoeSān cosmology but identifying exactly what that role is and how it relates to different contexts of belief and action is more challenging. This article identifies a special role for birds in KhoeSān thought and practice, which is tightly bound to matters of spirit and healing, seems relatively cohesive and is distinctive and widespread, both culturally and historically. Working out from a detailed KhoeSān medical ethnography and using bird examples taken from a wide range of KhoeSān, I argue that bird relationships are best understood by re-framing popular ideas of 'supernatural potency' within persistent habits of perception and the opportunities or challenges they present. I further highlight how KhoeSān interaction with birds must be linked to particular relationships with knowledge in order to understand why birds are so salient. I conclude by emphasizing the dangers of explaining KhoeSān bird relationships within potentially distorting categories of 'metaphor'.

\section{RÉSUMÉ}

Il n'est pas surprenant que les animaux aient joué un rôle important dans la cosmologie khoesan, mais il est plus difficile d'identifier exactement ce qu'est ce rôle et comment il s'articule avec les différents contextes de croyance et d'action. Cet article identifie un rôle spécial pour les oiseaux dans la pensée et la pratique khoesan, étroitement lié aux choses de l'esprit et de la guérison, relativement cohésif en apparence, et distinctif et répandu tant d'un point de vue culturel qu'historique. S'inspirant d'une ethnographie médicale khoesan détaillée et d'exemples d'oiseaux extraits d'un large éventail khoesan, l'article soutient que le meilleur moyen de comprendre les relations afférentes aux oiseaux est de réinterpréter les idées populaires de "puissance surnaturelle " au sein des habitudes de perception et les opportunités ou difficultés qu'elles présentent. L'article souligne par ailleurs la nécessité de lier l'interaction Khoesan-oiseaux à des rapports particuliers avec la connaissance pour comprendre pourquoi les oiseaux sont si saillants. Il conclut en insistant sur le danger à expliquer les relations Khoesan-oiseaux dans le cadre de catégories de "métaphores " potentiellement déformantes. 